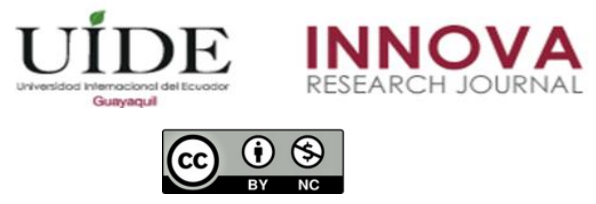

INNOVA Research Journal, ISSN 2477-9024

(Septiembre - diciembre 2019). Vol. 4, No.3 pp. 193-209

DOI: https://doi.org/10.33890/innova.v4.n3.2019.1008

URL: http://revistas.uide.edu.ec/index.php/innova/index

Correo: innova@uide.edu.ec

\title{
Análisis del Método de Comunicación Externo de la marca Analucila Jewelry Design
}

\section{Analysis of the External Communication Method of the Analucila Jewelry Design brand}

María Stefanie De la Vera Guillén

Consultor Independiente, Ecuador

Kerlly Teresa Yance Jácome

Universidad Tecnológica ECOTEC, Ecuador

Fernando José Zambrano Farías

Universidad Internacional del Ecuador, Ecuador

Universidad de Guayaquil, Ecuador

Autor para correspondencia: stefdvg@gmail.com; kyance@ecotec.edu.ec;

fezambranofa@uide.edu.ec; fernando.zambranofar@ug.edu.ec

Fecha de recepción: 23 de mayo del 2019 - Fecha de aceptación: 29 de agosto del 2019

\section{Resumen}

La marca Analucila Jewelry Design es una microempresa creada a inicios del año 2017 que tiene como actividad principal el diseño y comercialización de joyas semi-finas y finas, pero en la actualidad presenta la necesidad de diferenciarse de la competencia para de esta manera fortalecer la imagen de su marca debido al constante crecimiento de negocios que ofrecen la misma categoría de producto, sin contar con una marcada diferenciación en relación a la competencia, por tal motivo a través de la presente investigación se pretende analizar el método de comunicación externo para el fortalecimiento de su imagen, a fin de proyectar una percepción positiva para su público externo actual y potencial, para lo cual se realizará un diagnóstico con el propósito de entender su identidad de marca y evaluar la estrategia de comunicación que mantiene con su público; permitiendo de esta manera descubrir la percepción que se tiene de la misma con la finalidad de garantizar el buen desempeño y desarrollo del plan de comunicación externa en caso de requerirse. En el desarrollo de la investigación se abordan los conceptos de comunicación, sus procesos, tipos y elementos, también se trata sobre la identidad corporativa, su concepto y factores que la integran. En la presente investigación se empleó la investigación exploratoria, a través de la metodología cualitativa aplicando la técnica Focus Group y la técnica de entrevistas a líderes de opinión tales como profesionales en asesoría de imagen, diseñadores y bloggers de moda, entre otros, así como también se aplica la investigación descriptiva con la metodología cuantitativa usando la técnica de encuestas al público por medio de las redes sociales.

Palabras claves: marca; imagen; estrategias; comunicación externa; microempresa 


\begin{abstract}
The Analucila Jewelry Design brand is a micro-enterprise created at the beginning of 2017 that has as its main activity the design and commercialization of semi-fine and fine jewels, but currently presents the need to differentiate itself from the competition in order to strengthen the image of its brand due to the constant growth of businesses that offer the same category of product, without having a marked differentiation in relation to the competition, for this reason through this research it is intended to analyze the method of external communication for the strengthening of its image, in order to project a positive perception for its current and potential external audience, for which a diagnosis will be made in order to understand its brand identity and evaluate the communication strategy it maintains with its audience; allowing in this way to discover the perception that one has of it with the purpose of guaranteeing the good performance and development of the external communication plan if required. In the development of the research, the concepts of communication, their processes, types and elements are addressed, it is also about the corporate identity, its concept and factors that integrate it. In this research, exploratory research was used, through the qualitative methodology applying the Focus Group technique and the technique of interviews with opinion leaders such as image consulting professionals, designers and fashion bloggers, among others, as well as Descriptive research is applied with the quantitative methodology using the public survey technique through social networks.
\end{abstract}

Key words: brand; image; strategies; external communication; microenterprise

\title{
Introducción
}

En la actualidad la comunicación es un elemento principal en todas las organizaciones, por lo que gestionarla de una manera adecuada lograría alcanzar los objetivos, por tal motivo a través de la presente investigación se analiza el método de comunicación externo que en la actualidad aplica la marca Analucila Jewerly Design, , con mayor énfasis en el mercado guayaquileño, para lo cual se realizará un diagnóstico con el propósito de entender su identidad de marca y evaluar la estrategia de comunicación que mantiene con su público; permitiendo de esta manera descubrir la percepción que se tiene de la misma con la finalidad de garantizar el buen desempeño y desarrollo del plan de comunicación externo.

En el desarrollo se abordan los conceptos de comunicación, sus procesos, tipos y elementos. También se trata sobre la identidad corporativa, su concepto y factores que la integran, a qué se refiere cuando se habla de misión y visión, qué es la reputación. Además se habla sobre la marca en cuestión: Analucila Jewelry Design, su historia, sus orígenes, cuál es su estructura funcional, cuál es su tamaño, cómo se maneja en el mercado, cuál es la imagen que desea transmitir a su público objetivo, los productos y servicios que ofrece a los ecuatorianos.

Para el presente trabajo, se emplea la investigación exploratoria, a través de la metodología cualitativa aplicando la técnica Focus Group y la técnicas de entrevistas a líderes de opinión tales como profesionales en asesoría de imagen, diseñadores y bloggers de moda, entre otros, así como también se aplica la investigación descriptiva con la metodología cuantitativa usando la técnica de encuestas al público por medio de las redes sociales, Además se muestran las gráficas elaboradas con base en los resultados obtenidos de las encuestas realizadas. 


\section{Desarrollo}

El sistema de comunicación externa para la marca Analucila Jewelry Design, es una iniciativa dirigida a la promoción y fortalecimiento de imagen. Para poder materializar de forma efectiva las estrategias y actividades que este sistema contempla, es necesario hacer de la comunicación una herramienta fundamental y que a su vez sea un instrumento de medición de resultados y satisfacción en las personas beneficiadas por el plan.

En el desarrollo de este trabajo de investigación, se ha considerado necesario involucrar una serie de elementos teóricos y conceptuales que permitan alcanzar un proceso metodológico efectivo.

De esta manera, para lograr una difusión exitosa del actual sistema de comunicación externa para el fortalecimiento de la marca Analucila Jewelry Design se hace necesario conocer a fondo el concepto de comunicación, públicos, objetivos, stakeholders, plan de comunicación, imagen corporativa, identidad corporativa y todo lo que el mismo implica en pro de una aplicación oportuna y asertiva en este proceso investigación.

\section{Comunicación Organizacional}

La organización es una estructura sistemática concebida para crear objetivos y metas, conformada por grupos de personas que tienen tareas asignadas para el cumplimiento de propósitos específicos. La clasificación de ésta puede ser según su finalidad, estructura, tamaño, propiedad y actividad económica.

"La comunicación organizacional es aquella que establecen las instituciones y forma parte de su cultura o de sus normas." (De Castro, 2016, p.15). Entre los canales de comunicación más comunes en las organizaciones existen, el memorándum, reuniones, correo electrónico, teléfono, entre otras. Y a su vez existen dos tipos de comunicación dentro de las organizaciones, la formal e informal.

Los procesos comunicativos realizados en el interior del sistema organizativo constituyen la comunicación interna, dirigida a conseguir una estabilidad en la organización con vistas a que se alcancen sus fines. Por medio de la comunicación se logra crear y mantener la cultura de la organización. Igualmente, la comunicación es el modo fundamental de transmitir la cultura y conseguir la socialización de los miembros (Trelles, 2004).

La comunicación dentro de una organización debe ser efectiva pues beneficia a todos los elementos de una institución, permitiendo a los trabajadores realizar sus actividades como mayor motivación y rendir más en su desempeño. La mayoría de los problemas existentes en una organización es el mal manejo de la comunicación dentro de la misma. 


\section{Objetivos de la comunicación organizacional}

El mundo acelerado y cambiante ha hecho que los objetivos de la comunicación organizacional de ahora no sean los mismos que hace diez años atrás, por lo tanto, los objetivos se deben regir a partir de otros parámetros, así lo asegura (Álvarez, 2013).

Dentro de los tipos de comunicación organizacional, se hará énfasis en la Comunicación Organizacional externa.

\section{Comunicación organizacional externa}

La comunicación organizacional externa tiene “...la función de catalizar las relaciones interpersonales y entre instituciones, que se dan en el ámbito organizacional..." (Ávila González, 2004, p. 145). Es decir que provoca una reacción de cualquier tipo en el mensaje que se transmite, sea esta favorable o desfavorable para la empresa. Esta comunicación externa tiene tres tipos que se presentan a continuación:

\section{Tipologías que puede adoptar esta comunicación externa}

\section{Comunicación externa operativa}

Es la cual se realiza para el desenvolvimiento diario de la actividad empresarial, es decir su diario vivir y se efectúa con todas las fuerzas externas de la compañía: clientes, proveedores, competidores, administración pública, etc. (Com Organizacional, 2017).

\section{Comunicación externa estratégica}

Es la comunicación que tiene por finalidad enterarse de los datos de la competencia, la evolución de las variables económicas, los cambios en la legislación laboral, etc., se denomina estratégica debido a que estos datos servirán para la toma de decisiones en la organización que la obtiene.

\section{Comunicación externa de notoriedad}

Su finalidad dar a conocer sus productos, su imagen, sus servicios, promociones y descuentos. Las formas de darlo a conocer serían mediante la publicidad, promoción, donaciones, patrocinios, etc. (Com Organizacional, 2017).

\section{Imagen corporativa}

Analizando el concepto de imagen solamente, se puede manifestar que es una representación visual o mental de algún elemento o situación, en este caso se refiere a la imagen de una organización, la cual es el producto de las estrategias adoptadas y empleadas.

Ahora pues, la imagen corporativa según Sanz de la Tajada (2002) desde el punto de vista mediático, es una forma de conocer indirectamente a la organización, este concepto permitirá a 
los públicos conocerla y evaluarla, tanto a ella como a sus productos y/o servicios. Desde otro punto de vista, la imagen corporativa es la percepción que tiene el público acerca de la organización, es lo que representa la compañía en la sociedad. En muchos casos el departamento encargado de manejar la imagen corporativa es el área de relaciones públicas.

Esta representación tiene varias funciones en la cuales se pueden destacar el concepto de la identidad, imagen del producto, de marca, de empresa: Identidad de la empresa, comunicación de la empresa, realidad de la empresa.

La imagen corporativa debe estar en constante cambio y renovación para lograr mantenerse en la mente de los púbicos y que el nivel de recordación de la marca sea más elevado, también se debe cuidar y estudiar si la imagen que se está proyectando le está llegando de manera correcta al receptor.

\section{Identidad corporativa}

Según (Sanz de la Tajada, 2002, pág. 137) La identidad corporativa de una empresa es “...el conjunto de representaciones tanto afectivas como racionales que un individuo o un grupo de individuos asocian a una empresa o a una marca". Esto quiere decir que es la forma que se proyecta una organización y abarca los aspectos culturales, ambientales y de comportamiento.

La identidad se la relaciona con la personalidad de la empresa, y la imagen como requisito físico y conceptual de la empresa en relación a sus competidores y su marca.

\section{Los públicos}

Es el mercado al cual va dirigido un determinado producto o servicio, la (Real Academia Española, 2014) define a público como "Conjunto de las personas que participan de unas mismas aficiones o con preferencia concurren a determinado lugar. Cada escritor, cada teatro tiene su público". De este concepto se puede desprender uno muy utilizado en los últimos años, stakeholders el cual se menciona a continuación.

\section{Stakeholders}

Según González (2010) Los stakeholders de una organización son todos los grupos que tienen interés en la misma, como los accionistas, los empleados, los clientes, los distribuidores, los proveedores, la comunidad, los gobiernos, los grupos de presión, etc. (p.57)

Dicho en otras palabras, los stakeholders son los grupos que de una u otra forma aportan a la empresa, sean estos aportes positivos o negativos, estos grupos pueden ser de personas, organizaciones o empresas.

La identificación de los públicos y la selección del público objetivo es un trabajo que debe hacer la organización de modo que sepa el tipo de estrategias comunicacionales que se deben emplear para cada uno de ellos. (Míguez González, 2010). Haciendo que las estrategias del plan tengan resultados más eficaces y eficientes. 


\section{Estrategias de comunicación}

Según (Ferré Trenzano \& Ferré Nadal, 1996) "La forma en que unos determinados objetivos de comunicación son traducidos en lenguaje inteligente para nuestro público receptor, para que los pueda asimilar debidamente" (p.11) es una estrategia de comunicación. Esto quiere decir que se debe estudiar debidamente la forma en la cual se da el mensaje al público para poder tener una respuesta positiva por parte del receptor.

Si bien es cierto no existe la estrategia perfecta ni definitiva por el mundo tan cambiante en el cual vivimos. Pero Ferré Trenzano \& Ferré Nadal en su libro "Políticas y estrategias de comunicación y publicidad, (1996) muestran las ocho ideas de estrategias comunicacionales más utilizadas:

Originalidad, empatía, agresividad, creatividad, garantía, símbolos visuales, convicción, unicidad (una sola idea)

\section{Plan de comunicación y sus elementos}

Un plan o método de comunicación según Sanz de la Tajada ( 2002) Concibe a la comunicación empresarial como un todo que involucra dos ámbitos, el primero es el comercial: Perspectiva del marketing, en el cual se destaca la publicidad; y, el segundo es el general y más amplio de la empresa: Perspectiva del Management, que integra lo comercial con el ámbito general de la empresa, coordina la comunicación comercial con la institucional e incorpora un plan de relaciones públicas y de publicidad corporativa al Plan Integral de la Comunicación.

No existe un formato definido para elaborar un plan comunicacional, pero si existen elementos que deben ser incluidos en su estructura, los cuales se detallan a continuación:

Análisis del Entorno, Antecedentes, Objetivos, Público objetivo El mensaje, Estrategia, Tácticas, Cronograma o calendario, Presupuesto, Control y seguimiento, Imagen corporativa

Analizando el concepto de imagen solamente, se puede manifestar que es una representación visual o mental de algún elemento o situación, en este caso se refiere a la imagen de una organización, la cual es el producto de las estrategias adoptadas y empleadas.

Ahora pues, la imagen corporativa según Sanz de la Tajada (2002) desde el punto de vista mediático, es una forma de conocer indirectamente a la organización, este concepto permitirá a los públicos conocerla y evaluarla, tanto a ella como a sus productos y/o servicios. Desde otro punto de vista, la imagen corporativa es la percepción que tiene el público acerca de la organización, es lo que representa la compañía en la sociedad. En muchos casos el departamento encargado de manejar la imagen corporativa es el área de relaciones públicas.

Esta representación tiene varias funciones en la cuales se pueden destacar el concepto de la identidad, imagen del producto, de marca, de empresa: Identidad de la empresa, comunicación de la empresa, realidad de la empresa. 
La imagen corporativa debe estar en constante cambio y renovación para lograr mantenerse en la mente de los púbicos y que el nivel de recordación de la marca sea más elevado, también se debe cuidar y estudiar si la imagen que se está proyectando le está llegando de manera correcta al receptor.

\section{Metodología}

En el presente trabajo se aplicaron dos tipos de investigación, exploratoria y descriptiva.

Se empleó el método de recolección de información cualitativo, en el cual, la recolección de datos consiste en obtener las perspectivas y puntos de vista de los participantes (Hernández Sampieri, 1991, pág. 8), aplicando la técnica del Focus Group y la técnica de entrevistas a líderes de opinión tales como profesionales en asesoría de imagen, diseñadores y bloggers de moda. Esto con el fin de profundizar en el tema, conocer punto de vista referente a la moda y, gustos y preferencias, para así dar paso a un estudio más extenso que se llevará a cabo mediante encuestas

Después de realizar una indagación exploratoria, llega el momento de realizar una investigación más profunda y esto se puede efectuar realizando una investigación descriptiva, en la cual "Se busca especificar las propiedades, las características y los perfiles de personas, grupos, comunidades, procesos, objetos o cualquier otro fenómeno que se someta a un análisis." (Hernández Sampieri, Fernández Collado, \& Baptista Lucio, 2014, p. 81)

En la investigación descriptiva se aplicó la metodología cuantitativa debido a que los datos de recolección son numéricos y se analizan mediante procedimientos estadísticos, para esto se ha usado la técnica de encuestas al público por medio de las redes sociales, y se muestran los resultados mediante las gráficas estadísticas elaboradas.

\section{Población y Muestra}

Para determinar el público objetivo al cual se dirigen las estrategias contenidas en este plan comunicacional, hay que definir la población y la muestra; para ello se ha considerado como población al número de seguidores que tiene la página de Instagram de la empresa, siendo estos los stakeholders directos debido a que pueden ver todas las publicaciones y actualizaciones que realiza Analucila Jewelry Design.

Analucila Jewelry Design tiene actualmente 1791 seguidores, esta cantidad de seguidores va a variar con el paso del tiempo, pero para el presente estudio se ha tomado como referencia. El tipo de muestra que se consideró para esta investigación es aleatoria, se trabajó con un nivel de confianza del $95 \%$ y un error típico del 5\% que son los datos estándares y generalmente aceptados para estos trabajos, cuya fórmula es la que se presenta a continuación:

$$
n=\frac{Z_{\alpha / 2}{ }^{2} p q N}{e^{2}(N-1)+Z_{\alpha / 2}{ }^{2} p q}
$$


El valor de p y q es un dato desconocido debido a que no se sabe si el encuestado es cliente o no de Analucila, por lo que se supone que es el 50\% de ocurrencia como dato más seguro. Por lo tanto los datos obtenidos son los siguientes:

$$
\begin{aligned}
& \mathrm{N}=1791 \text { personas } \\
& \alpha=95 \% \rightarrow \mathrm{z} \alpha / 2=1.96 \\
& \mathrm{p}=0.5 \\
& \mathrm{q}=0.5 \\
& \mathrm{e}=5 \%
\end{aligned}
$$

Reemplazando en la fórmula se obtiene lo siguiente:

$$
n=\frac{\left(1.96^{2}\right)(0.5)(0.5)(1791)}{0.05^{2}(1791-1)+\left(1.96^{2}\right)(0.5)(0.5)}=316
$$

Resultado: La muestra dio como resultado 316 personas que son seguidoras de la página de la empresa

\section{Trabajo de Campo}

Para este trabajo se utilizaron tres métodos de recolección de datos: entrevistas, Focus Group y encuestas. A continuación, se describe la aplicación de cada uno de estos métodos.

\section{Entrevistas}

Dichas entrevistas se las realizó a las reconocidas influencers Nabila Orellana Blogger de Moda ecuatoriana y a Sophy Castañeda Lcda. en imagen personal, con el fin de obtener opiniones de expertos en el tema de la moda y tendencias en cuanto a accesorios y joyas para la época actual que servirá como guía para futuras estrategias de producto y diseño de los mismos.

La autora (Blanco, 2016) define a los influencers como "Una nueva ola de profesionales con gran notoriedad, influencia e impacto en la moda, la belleza, el lifestyle... Tienen la capacidad de movilizar a miles de seguidores, condicionar decisiones de compra y marcar el ritmo en la red. En un mundo de tantas oportunidades, la competencia es feroz y detectar a los verdaderos especialistas no resulta una tarea sencilla" (p. 6).

\section{Focus Group}

Para este trabajo investigativo, se realizó un Focus Group con la participación de 6 mujeres entre 20-80 años, con la característica que utilizan accesorios; a fin de conocer las expectativas que los entrevistados tienen con la marca, sus experiencias con la misma y sugerencias en cuanto al servicio y producto que se ofrece. 


\section{Encuestas}

La encuesta se realizó de forma aleatoria a través de mensajes internos a los seguidores de la cuenta en Instagram, los que se han verificado que son reales por su interés en las publicaciones dando like, comentando y pidiendo información ya sea en la foto de la publicación o por interno.

\section{Resultados}

El presente capítulo muestra los resultados obtenidos del trabajo de campo, se emplearon tres técnicas de recolección de datos, los cuales se presentan a continuación.

\section{Focus Group}

El grupo focal se realizó tuvo la participación de seis mujeres entre 20-80 años que como característica común utilizan accesorios frecuentemente, y se obtuvieron los siguientes resultados:

Con la información recabada se puede concluir que el mayor porcentaje de los clientes se dejan llevar por el diseño del producto, el precio y luego por las ofertas, esto evidencia que son los factores más importantes y a los que hay que prestar mayor atención a la hora de ofertar los productos.

Entre las marcas más recordadas de las invitadas al grupo focal se pueden mencionar Isabela, Yanbal, Dore, Lbel, D Plata \& Complements Midas y Marthalia; esto da una referencia de cuáles son los competidores directos de Analucila y a cuales hay que poner más atención.

La mayor parte de las invitadas indicó que realizan sus compras en una tienda física, seguido de catálogos y stands en ferias, ninguna de las invitadas aseguró que su modo de compra es el on-line aunque no descartan el hecho de poder realizar una compra por esta plataforma. Esto hace llegar a la conclusión que las tiendas físicas tienen una ventaja sobre las tiendas online que no cuentan con un espacio físico para realizar sus actividades de venta, por lo que se puede estar estudiando la posibilidad de adquirir un local propio como estrategia de ventas directas.

Se pudo evidenciar que el tiempo de entrega frecuente en el ámbito on-line es una semana y las personas que no han realizado hasta ahora compras on-line no descartan la posibilidad de hacerlo y de esperar una semana hasta la entrega del producto, por lo que se puede pensar en una estrategia para dar a conocer a más personas los beneficios de comprar on-line sin miedos.

En la sesión se mostró una cadena totalmente personalizada cuyo valor es $\$ 65.00$, solo dos personas dieron un aproximado del valor real, mientras las demás colocaron valores debajo del real, esto se debe a que no se especificó el material del cual estaba hecho dicho accesorio, y esto hace llegar a la conclusión de que es importante indicarle al cliente que tipo de producto está adquiriendo, cual es el proceso de elaboración y cuál es su calidad, no solo mostrarlo sin definir sus características. 


\section{Entrevistas}

Se realizó una entrevista a la Blogger de moda ecuatoriana Nabila Orellana y a la Licenciada en Imagen Personal Sophy Castañeda, ambas reconocidas influencers en los medios digitales de Ecuador, por manejar cuentas personales de moda y estilo.

Por ser personas que siempre están a la moda y pendientes de las tendencias en cuanto a accesorios se puede decir que las joyas forman parte importante en el outfit diario, sin importar el lugar donde acudan, ya sea a reuniones, trabajo, universidad o algún evento social.

La Blogger nos comentó que los accesorios son importantes al momento de completar un outfit; ya que los aretes resaltan el rostro y las cadenas logran ser el complemento perfecto.

Para la Licenciada Castañeda lo más importante al momento de comprar un accesorio es la originalidad y versatilidad de este, esto da una idea de cuáles son los atributos que se pueden destacar en la marca para captar mayor número de clientes.

Ambas coinciden que la marca Analucila Jewelry Design transmite una imagen fresca, juvenil y delicada por lo que va bien para utilizarla a diario y estas opiniones concuerdan con la imagen que se ha querido transmitir a lo largo de su existencia.

Las cadenas y los aretes son los productos que más han gustado a las entrevistadas, por lo que los productos si animan a generar la acción de compra.

Los consejos brindados por las entrevistas han sido en cuanto a la publicidad ya que consideran que falta un poco más, en este caso Nabila sugiera que la marca se dé a conocer realizando publicidad de BTL, participando en mercaditos y ferias o showroom; mientras que la sugerencia de Sophy es actualizar las publicaciones de la página y colocar un fondo negro para resalten las joyas.

Una de las entrevistas consideraría a la marca Analucila Jewelry Design una de sus cuentas top; mientras que la otra indica que le falta más intensidad a la marca, por lo que uno de las estrategias será la creación de publicaciones con mayor impacto visual.

\section{Encuestas}

Estas encuestas se realizaron, utilizando las plataformas digitales como WhatsApp e Instagram y se pudo evidenciar que existe una clara preferencia de los aretes como accesorios, además de ser utilizados diariamente son un complemento perfecto para todo outfit. La calidad más utilizada por las usuarias es la plata con baño de oro además de afirmar que el precio de este influye mucho en su decisión de compra.

Por otro lado las encuestadas indicaron el medio por el cual conocieron Analucila es el Instagram, convirtiéndose este en su medio principal para generar el deseo de compra. Los resultados también indican que la página de Instagram tienen buenas críticas y el producto también en cuanto a la calidad, presentación y tiempo de entrega lo que da como conclusión que 
en calidad y diseño, Analucila está bien posicionada, sin embargo existen muchas personas que no conoce la marca y los servicios que presta lo que hace aún más prioritario este plan comunicacional para fortalecer la marca y crear recordación en los posibles compradores.

A continuación, se presenta el análisis de las encuestas realizadas a 316 personas que dieron los siguientes resultados:

- ¿Qué tipo de accesorios (joyas) son las que más utilizas?

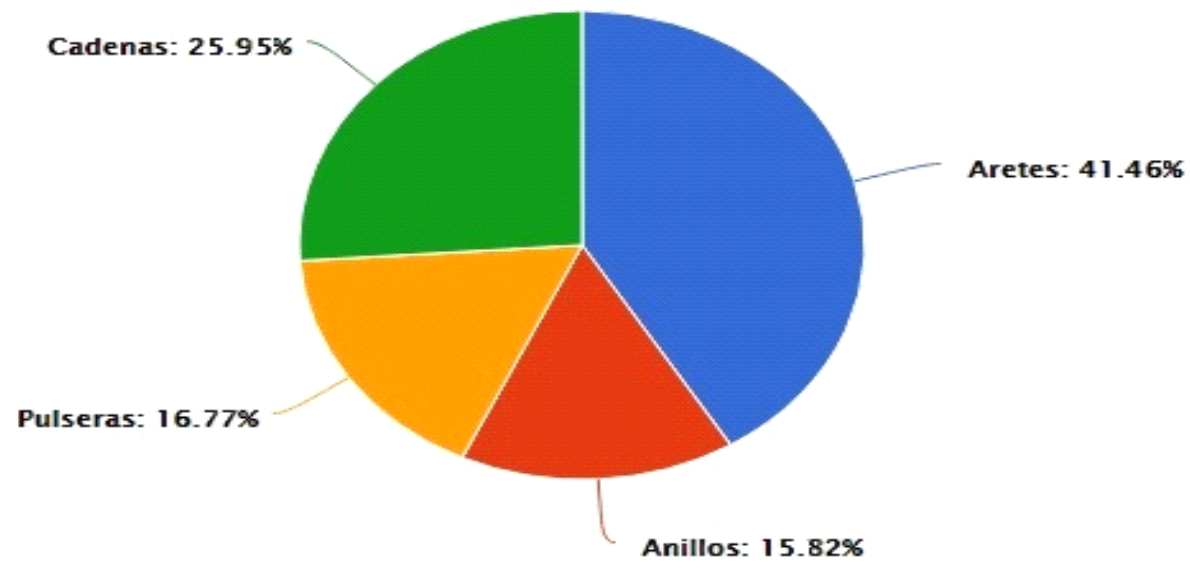

Figura 1 Accesorios más utilizados Elaborado por: Autores

Los accesorios más utilizados por las personas encuestadas son los aretes con un $41.46 \%$, seguido por las cadenas con un $25.95 \%$, después viene las pulseras con un $16.77 \%$ y al final con un $15.82 \%$ los anillos. Claramente se evidencia un favoritismo por los aretes debido a que es un accesorio muy pequeño y cómodo que es utilizado para cualquier ocasión, por lo que la marca puede crear una nueva colección solo de aretes para captar este amplio mercado.

- ¿Con qué frecuencia usas los accesorios señalados anteriormente?

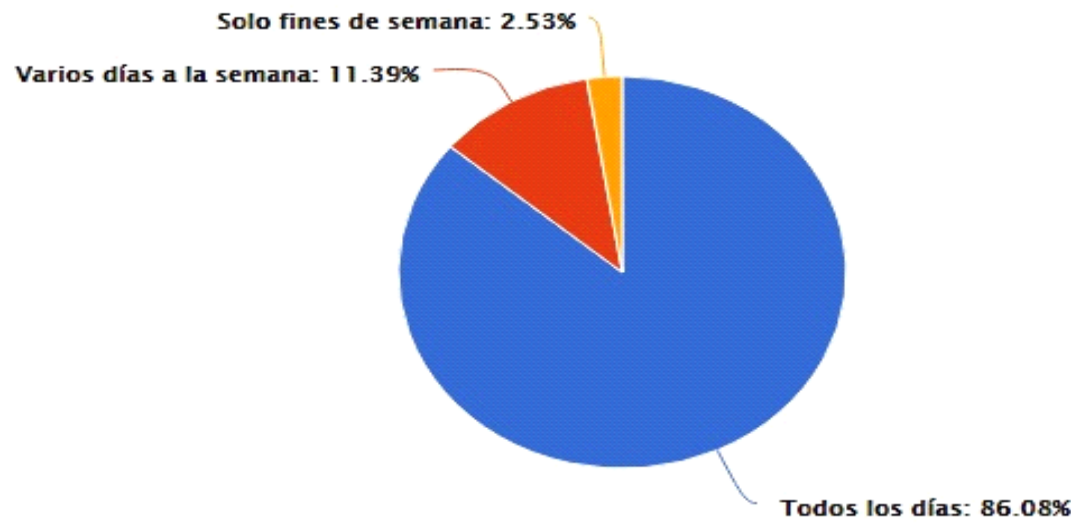

Figura 2 Frecuencia de uso Elaborado por: Autores 
El 86.08\% de las encuestadas manifestaron que utilizan sus accesorios todos los días, el $11.39 \%$ varios días a la semana y el $2.53 \%$ solo los fines de semana, esto da como conclusión que un accesorio va más allá de ser una vanidad, es más bien un complemento del vestuario que la mayoría de las mujeres utilizan en su diario vivir.

\section{- ¿En qué tipo de material compras tus accesorios?}

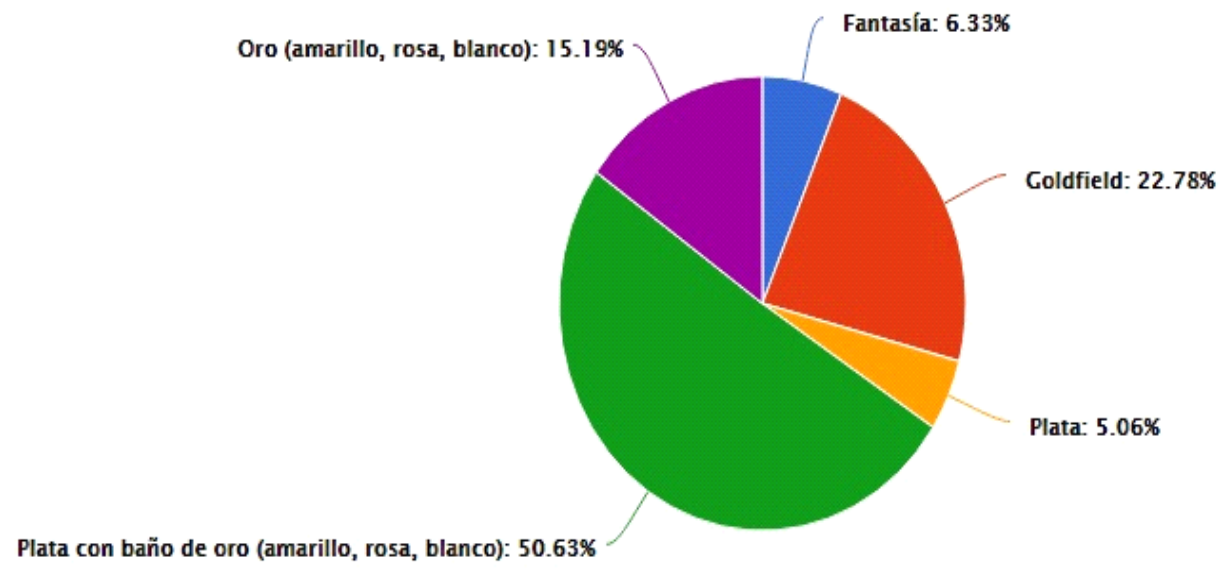

Figura 3 Material de los accesorios

Elaborado por: Autores

El material favorito entre los usuarios es la plata con baño de oro con un $50.63 \%$ de aprobación, después el Golfield con un $22.78 \%$, luego el oro con un $15.19 \%$ y por último la fantasía y la plata con un $6.33 \%$ y $5.06 \%$ respectivamente. Tomando en cuenta los gustos de los consumidores, se puede ofertar más productos de plata con baño de oro.

\section{- ¿El valor del accesorio influye en tu compra?}

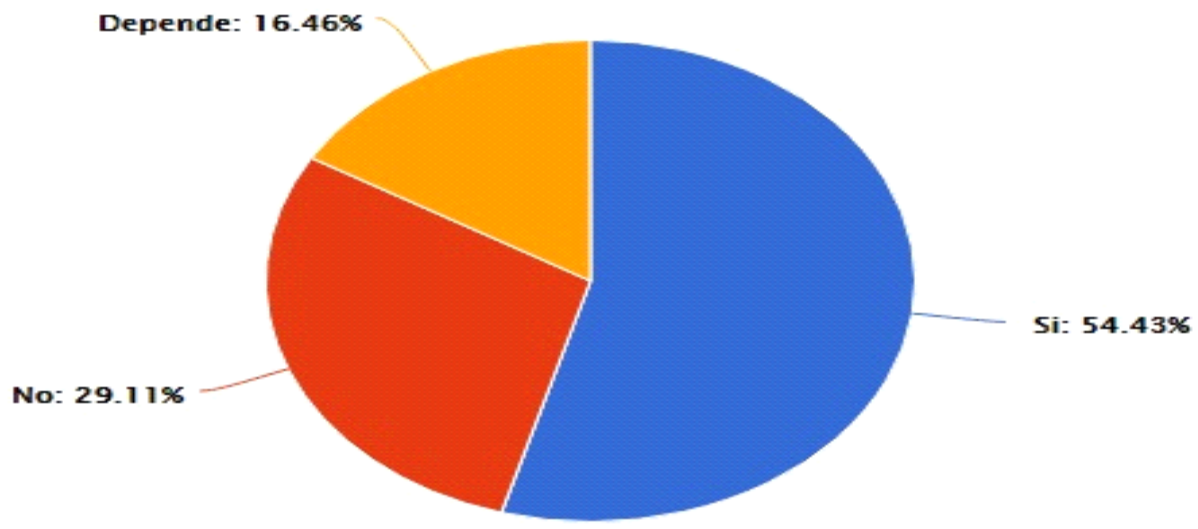

Figura 4 Influencia del valor de compra Elaborado por: Autores

El precio del producto si influye en la acción de compra del mismo, ya que el $54.43 \%$ así lo afirman, el $29.11 \%$ indica que no influye, y por otro lado existe un $16.46 \%$ que indica que 
depende de la situación, como esta respuesta tenía una condición abierta, algunas personas mostraron sus motivos e indicaron lo siguiente, depende del "modelo". "objetivo de la compra", "regalos", "gustos", diseño", etc.

\section{- ¿Por qué medios conociste Analucila?}

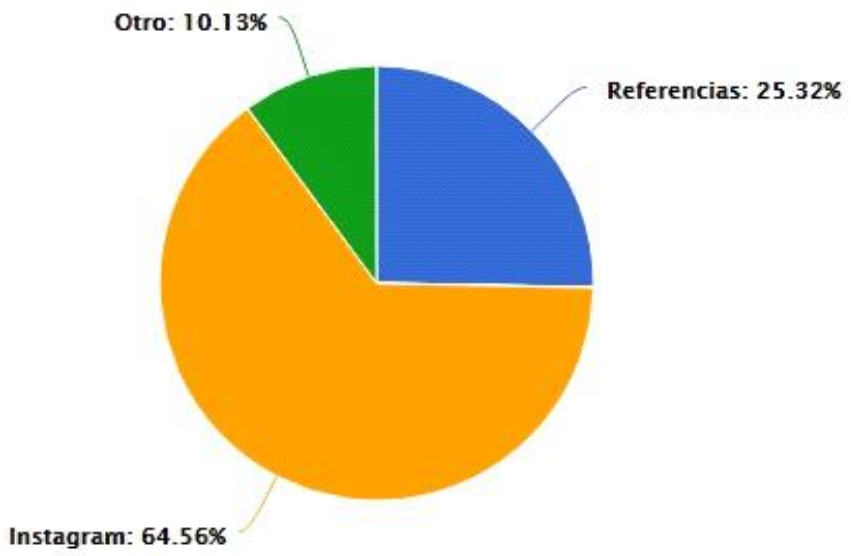

Figura 5 Medios de comunicación Elaborado por: Autores

El medio por el cual conoce la mayor parte de los encuestados a Analucila es el Instagram (64.56\%), siendo esta la plataforma en la cual se suben los post, se realizan ventas y se da a conocer el producto, por otro lado también conocen a la marca por referencias personales $(25.32 \%)$ y por otros medios con un $(10.13 \%)$.

Esto da como conclusión que Analucila tiene un campo más amplio para que sea conocida, ya que no ha abarcado el campo de la publicidad ATL en televisión y radio y se pueden formular estrategias de este tipo para que más personas conozcan la marca.

\section{- ¿Has comprado en Analucila?}

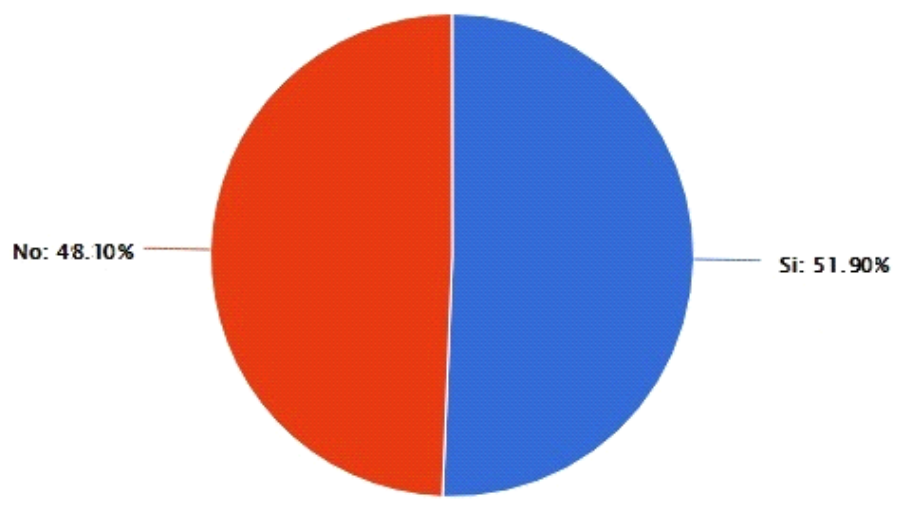

Figura 6 Compras

Elaborado por: Autores 
El $51.90 \%$ de los encuestados han comprado en Analucila, esto indica que esta cantidad puede subir, debido a que la población estudiada son los seguidores de Instagram, por lo tanto la estrategia de publicaciones en redes sociales viene bien para comunicar las novedades de la marca

- En relación al producto, presentación y tiempo de entrega, ¿Cómo calificaría a Analucila? siendo 5 el mayor puntaje.

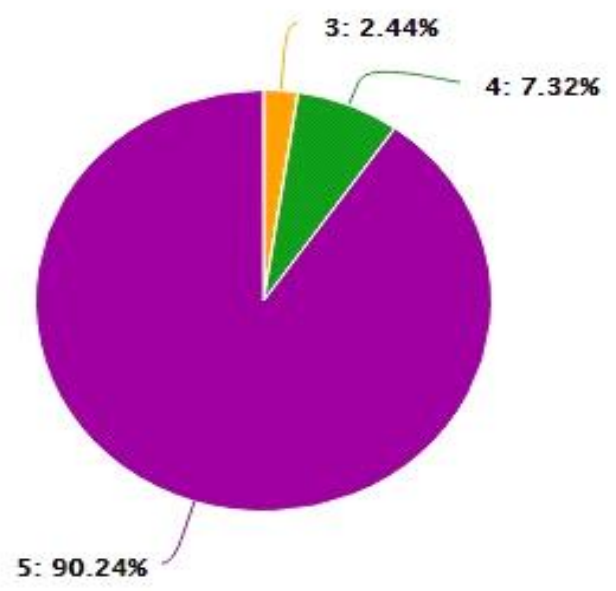

Figura 7 Celeridad en entrega de producto

Elaborado por: Autores

Producto: La percepción en cuanto al producto es excelente debido a que el $90.24 \%$ coinciden en esta premisa.

Presentación: La percepción en cuanto a la presentación es excelente debido a que el $80.49 \%$ coinciden en esta premisa.

Tiempo de entrega: La percepción en cuanto tiempo de entrega es excelente debido a que el $90.24 \%$ coinciden en esta premisa. 


\section{- ¿Cómo fue la atención brindada?}

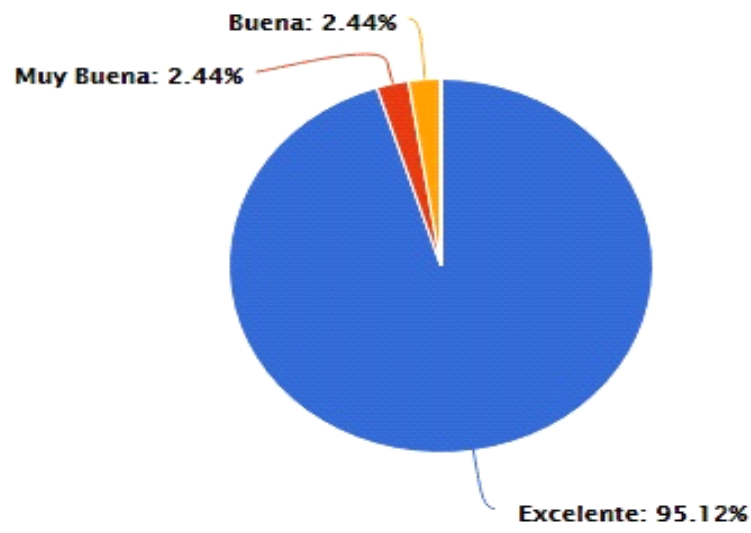

Figura 8 Percepción de la atención al cliente

Elaborado por: Autores

Los usuarios tienen una excelente percepción de la atención al cliente que brinda la joyería (95.12\%), esto se puede tomar como una Fortaleza, ya que no todas las empresas gozan de un cliente totalmente satisfecho en cuanto a la atención brindada.

\section{- ¿Recomendarías esta marca?}

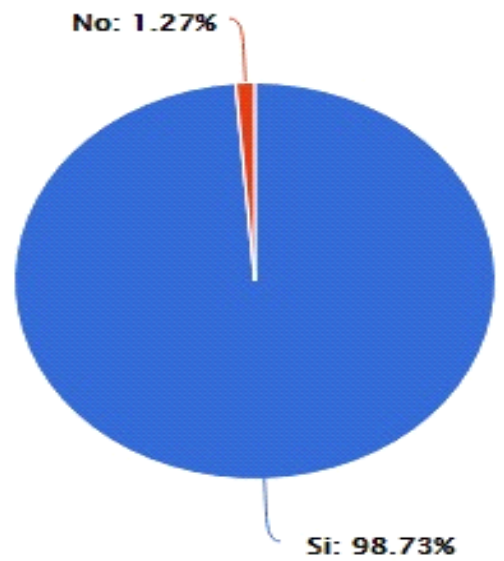

Figura 9 Recomendación de la marca Elaborado por: Autores

El 98.73\% de los encuestados recomendarían la marca a personas de sus circulos sociales, en tanto solo el $1.27 \%$ no lo haría, esto ya sea porque no conoce muy a fondo la marca o simplemente porque no recomiendan este tipo de producto, en todo caso también es muy bueno que la mayoría de las personas encuestadas tengan la predisposición de recomendar la marca ya que la publicidad boca a boca es tan o más importante que la publicidad en los medios. 


\section{Conclusiones}

La correcta aplicación de un buen método de comunicación externa contribuirá al fortalecimiento de la imagen de la marca no solamente en redes sociales sino que además se lo hará en medios tradicionales lo que contribuirá al posicionamiento e incremento de las ventas.

Por medio de este trabajo de investigación se evidenció que para este tipo de mercado es necesario, aparte de un sistema de comunicación de externa eficaz, un espacio físico para poder exhibir la mercadería y que los clientes puedan apreciarla ya que a pesar de que los productos de Analucila están dirigidos a público de todas las edades, aún no se desarrolla de forma eficiente el comercio electrónico dentro de este nicho.

En un mercado competitivo y dinámico como en el que se encuentra Analucila, es de mucha importancia realizar un monitoreo del nivel de satisfacción de sus clientes y que ésta retroalimentación sirva para mejorar la calidad del servicio ofrecido así como para la innovación y oferta de mejores y nuevos productos, lo que conlleva al fortalecimiento y posicionamiento de la marca.

\section{Bibliografía}

Álvarez, J. (2013). Manejo de la Comunicación Organizacional. Madrid: Ediciones Díaz de Santos.

Andrade, H. (2005) Comunicación Organizacional Interna, proceso, disciplina y técnica. Netbiblo.

Ávila González, R. (2004). Critica de la comunicacion organizacional. Coyoacán: Universidad Nacional Autónoma de México.

Capriotti, Paúl. (1999). Planificación Estratégica de la Imagen Corporativa. Ariel

Capriotti, Paúl. (2009). Branding Corporativo. Ariel

Costa, J. (2004). Imagen de Marca. Ediciones Paidós

Ferré Trenzano, J. M., \& Ferré Nadal, J. (1996). Políticas y estrategias de comunicación y publicidad. Madrid: Ediciones Díaz de Santos.

Com Organizacional. (5 de 03 de 2017). Obtenido de http://estilosorganizados.es.tl/Importanciay-funciones-de-la-comunicacion-interna-y-externa.htm

De Castro, A. (2016). Manual práctico de Comunicación Organizacional. Madrid: Verbum.

Fernández Collado, C., \& Dahnke, G. (1986). La comunicación humana: ciencia social. México: McGraw-Hill.

Hernández Sampieri, D., Fernández Collado, D., \& Baptista Lucio, D. (2014). Metodología de la Investigación (6ta edición ed.). México D.F.: McGRAW-HILL / INTERAMERICANA EDITORES, S.A. DE C.V.

Hernández Sampieri, R. (1991). Metodología de la Investigación. Naucalpan de Juarez: McGRAW - HILL Interamericana de México.

Míguez González, M. I. (2010). Los públicos en las relaciones públicas. Barcelona: Editorial UOC.

Ongallo, C. (2007). Manual de Comunicación. Dykinson.

Pérez González, R. A. (2008). Estrategias de Comunicación. Ariel 
Real Academia Española. (Octubre de 2014). Diccionario. Recuperado el 5 de Agosto de 2016, de http://dle.rae.es/?id=BetrEjX

Sanz De La Tejada, L. Á. (2002). Integración de la identidad y la imagen de la empresa. Madrid: ESIC Editorial. 